\title{
Attitude and its Associated Factors Among Adults Towards Traditional Eye Medicine in Gondar City, North West Ethiopia
}

minychil Bantihun Munaw ( $\square$ minychilmedban@gmail.com )

University of Gondar

Dereje hayilu anbesse

University of Gondar

natnael lakachew assefa

University of Gondar

\section{Research Article}

Keywords: Attitude, Traditional Eye Medicine, Gondar City, Ethiopia

Posted Date: March 8th, 2021

DOI: https://doi.org/10.21203/rs.3.rs-287942/v1

License: (c) (i) This work is licensed under a Creative Commons Attribution 4.0 International License.

Read Full License 


\section{Abstract \\ Background}

Traditional medicines are commonly practiced in Africa. It is believed to be alternative health care used in the developing world. It is a more widely available and affordable alternative to pharmaceutical drugs. In Africa, about $13.2-82.3 \%$ of the population utilizes traditional eye medicine. This study aimed to assess attitude and its associated factors among adults towards traditional eye medicine in Gondar city, North West Ethiopia.

\section{Methods}

A community-based cross-sectional study was conducted on 600 study participants using a pre-tested structured questionnaire. Data analysis was performed using Statistical Package for Social Sciences (SPSS) version 20 computer software. Association and strength between the outcome variable and independent variables were determined using the odds ratio with a $95 \%$ confidence interval.

\section{Results}

A total of 633 subjects were included in the study with a $95 \%$ response rate. From the total study subjects, 292 (48.7\%) (95\% Cl: 44.7-52.7\%)) had a good attitude towards traditional eye medicine use. Variables like being male ( $\mathrm{AOR}=2.00(95 \% \mathrm{Cl}: 1.23-2.68)$ ), family history of traditional eye medicine use $(\mathrm{AOR}=3.31(95 \% \mathrm{Cl}: 2.01-5.47))$, availability of traditional healer $(\mathrm{AOR}=1.81(95 \% \mathrm{Cl}: 1.12-2.95))$ and absence of health insurance $(\mathrm{AOR}=1.63(95 \% \mathrm{Cl}$ : $1.14-2.55))$ were variables significantly associated with good attitude towards traditional eye medicine use.

\section{Conclusion}

The result of this study shows that attitude towards traditional eye medicine use for the treatment of eye disease was fairly good. It indicates that almost half of the study participants had a good attitude towards traditional eye medicine use. Even though the attitude is fairly good, still it needs improvement. Male sex, family history of traditional eye medicine use, availability of traditional healers, and absence of health insurance had a statistically significant relationship with good attitude towards traditional eye medicine use. Community awareness creation through the joint up effort by the health ministry of Ethiopia and traditional healers about traditional eye medicine use can help to build the right perception and reduce the risk of complications.

\section{Background}


World health organization defines traditional medicines as the total of all knowledge and practices whether explicable or inexplicable used in diagnosis, prevention and elimination of physical, mental or social imbalance and relying exclusively on practical experience and preservation handed down from generation to generation whether verbally or written (1).

Traditional eye medicines are a form of biologically based therapies or practices that are instilled or applied to the eye or administered orally to achieve a desired ocular therapeutic effect. Traditional eye medicines are crude or partially processed organic (plant and animal products) or inorganic (chemical substances) agents (2). The most common types of traditional eye medicines used by traditional eye medicine practitioners (TEMPs) are plant extracts, commercial chemicals, and fluids from various sources $(1,2)$.

Traditional eye medicine is common in Africa. It is believed to be alternative health care used in the developing world. It is a more widely available and affordable alternative to pharmaceutical drugs. In Africa, about $13.2-82.3 \%$ of the population utilizes traditional eye medicine (3-6).

Traditional eye medicine has been used in Ethiopian $(7,8)$. However, there is no study done specifically on attitude towards traditional eye medicine. Therefore, studying attitude and its associated factors among adults towards traditional eye medicine in Gondar city can provide important information to stakeholders to take appropriate controlling measures regarding the quality and safety of the practices.

\section{Methods}

\section{Study population and study design}

A community-based cross-sectional study was conducted in Gondar city. Gondar has located $727 \mathrm{Km}$ from the capital, Addis Ababa, and $182 \mathrm{~km}$ from Bahir Dar, the capital of Amhara National Regional State. According to the 2007 national central statistical agency, Gondar city has a population size of 351,675 and the city is subdivided into 24 city kebeles (local administrative) holding approximately 53,725 households and 112, 800 adult population. There is one governmental tertiary eye care center that provides different specialty eye care services and three private eye care specialty clinics in the city.

The study was conducted from April 25 to May 15, 2017. Adults' age $\geq 18$-years-old living in Gondar city, were the source population. Individuals who were unable to respond to the questionnaire due to either serious illness or mental problem and those who resided less than 6 months in the study area were excluded.

\section{Sample size determination and sampling procedure}

The sample size was determined by using open Epi computer software for a single population. By considering the proportion of good attitude towards traditional eye medicine use ( $P=50 \%$ ), a design effect of 1.5 and $10 \%$ of non-response rate, the final sample size was 633 . 
To select study participants, a multi-stage random sampling technique was employed in 24 homogenous kebeles (local administrative). Six kebeles were selected from the city by a simple random sampling technique. In selected kebeles, there were 12, 952 households. Population proportion to size sampling was used to determine the sample size in each kebeles. Households in kebeles were selected by a systematic random sampling method using a sampling fraction of 21 . Finally, the lottery method was used to select a participant in a household, where more than one adult ( $\geq 18$ years old) was found (Figure 1).

\section{Data collection tool and procedures}

Data collection was done by 6 trained diploma secretaries through a face to face interview, using a pretested structured Amharic (local language) Questionnaire. The data collection instrument (questionnaire) was developed in English for this study purpose and then translated to Amharic (local language) and later translated back to English by language experts to ensure the accuracy and reliability of data. To assure data quality, a pre-test ( $5 \%$ of the sample size) was done outside the study area on a similar population. The reliability of the questionnaire was tested using Cronbach's alpha and the result was 0.80. During a home to home visit to collect data, each data collector started by spinning a pen at a crossroads to select a specific direction. Besides, data clean up; checking for completeness, outliers, and missing values were done each day by the supervisor.

\section{Operational definitions}

Good attitude: A participant was said to have a good attitude towards traditional eye medicine use when he/she had scored mean and above the mean of attitude questions.

Poor attitude: A participant was said to have a poor attitude towards traditional eye medicine use when he/she had scored less than the mean of attitude questions.

Availability of traditional healer: A traditional healer was considered as available when a participant answered "yes" for the question "do you know a functional traditional healer?"

Health insurance: The participant was said to have health insurance when the participant has had an annual payment agreement with the government and the government covers the annual health cost of the participant.

\section{Data processing and statistical analysis}

Data from the entire questionnaire was coded, entered into Epi info 7, and exported to SPSS version 20 software for analysis. Frequency and cross-tabulations were used for the descriptive analysis of data. Associations between dependent and independent variables were analyzed using binary logistic regression with enter method variable selection. Variables with a P-value of $\leq 0.2$ in the bivariable analysis were entered into multiple logistic regressions and a variable with a P-value of $<0.05$ with a $95 \%$ confidence interval was considered as a statistically significant association. Model fitness was checked 
using Hosmer and Lemeshow goodness of fit and the result was 0.985 . Besides this, predictor variables were checked for multicollinearity and the variance inflation factor values were less than 10 through cross-checking across each variable.

\section{Results}

\section{Socio-demographic characteristics of study participants}

A total of 633 subjects were included in the study with a $95 \%$ response rate.

The median age of the participants was 30 (16 IQR) with a range of 18-88 years.

Among them, 354 (59\%) were females, 539 (89.8\%) were Christian in religion, and 426 (71\%) had income $\geq 1328$ Ethiopian birr (Table 1). 
Table 1

Sociodemographic characteristics of study participants among adults in Gondar city, North West Ethiopia, 2017 ( $n=600, n=$ No of study participants).

\begin{tabular}{|c|c|c|c|}
\hline Variables & Category & Frequency & Percent \\
\hline \multirow[t]{3}{*}{ Age (in years) } & $18-24$ & 150 & 25 \\
\hline & $25-30$ & 181 & 30.2 \\
\hline & $31-40$ & 140 & 23.3 \\
\hline \multirow[t]{2}{*}{ Sex } & $41-88$ & 129 & 21.5 \\
\hline & Male & 246 & 41 \\
\hline \multirow[t]{5}{*}{ Educational status } & Female & 354 & 59 \\
\hline & Can't read and write & 69 & 11.6 \\
\hline & Read and write & 99 & 16.6 \\
\hline & Primary school & 89 & 14.6 \\
\hline & Secondary school & 131 & 21.8 \\
\hline \multirow[t]{2}{*}{ Marital status } & Collage and above & 212 & 35.4 \\
\hline & Married & 307 & 51.1 \\
\hline \multirow[t]{3}{*}{ Religion } & Unmarried & 293 & 48.9 \\
\hline & Christian & 539 & 89.8 \\
\hline & Muslim & 61 & 10.2 \\
\hline \multicolumn{4}{|l|}{ Occupation } \\
\hline & Housewife & 109 & 18.2 \\
\hline & Student & 97 & 16.2 \\
\hline & Merchant & 115 & 19.2 \\
\hline & Employed & 203 & 33.8 \\
\hline & Other & 76 & 12.6 \\
\hline \multicolumn{4}{|l|}{ Income } \\
\hline & High income & 426 & 71 \\
\hline & Low income & 174 & 29 \\
\hline \multicolumn{4}{|c|}{ Community leadership role } \\
\hline & Yes & 115 & 19.5 \\
\hline
\end{tabular}




\begin{tabular}{clll}
\hline \multicolumn{1}{|l}{ Variables } & Category & Frequency & Percent \\
\hline & No & 485 & 80.5 \\
\hline Attitude towards traditional eye medicine use &
\end{tabular}

In the current study 292 (48.7\% (95\% Cl: $44.7 \%-52.7 \%)$ ) study participants had a good attitude towards traditional eye medicine use. From 600 total study participants, 294 (49\%) disagreed that traditional eye medicines are safer as modern eye medicines, and 340 (56.7 \%) disagreed that traditional eye medicines are more effective than modern eye medicines (Table 2). 
Table 2

Attitude of study participants towards traditional eye medicine use among adults in Gondar city, North West Ethiopia, 2017( $n=600)$.

\begin{tabular}{|c|c|c|}
\hline Questions & Frequency & Percent \\
\hline \multicolumn{3}{|c|}{ Do you accept traditional eye medicine use? } \\
\hline Yes & 274 & $45.7 \%$ \\
\hline No & 326 & $54.3 \%$ \\
\hline \multicolumn{3}{|c|}{ Do you encourage others to use traditional eye medicine? } \\
\hline Yes & 216 & $36.2 \%$ \\
\hline No & 384 & $63.8 \%$ \\
\hline \multicolumn{3}{|c|}{ Traditional eye medicines have a role in public eye health. } \\
\hline Strongly agree & 43 & $7.2 \%$ \\
\hline Agree & 254 & $42.2 \%$ \\
\hline Neutral & 79 & $13.2 \%$ \\
\hline Disagree & 181 & $30.2 \%$ \\
\hline Strongly disagree & 43 & $7.2 \%$ \\
\hline \multicolumn{3}{|c|}{ Individual or community perception of eye disease may encourage TEM use. } \\
\hline Strongly agree & 55 & $9.2 \%$ \\
\hline Agree & 172 & $28.6 \%$ \\
\hline Neutral & 44 & $7.4 \%$ \\
\hline Disagree & 278 & $46.3 \%$ \\
\hline Strongly disagree & 51 & $8.5 \%$ \\
\hline \multicolumn{3}{|c|}{ Traditional eye medicines are safer as modern eye medicines. } \\
\hline Strongly agree & 94 & $15.7 \%$ \\
\hline Agree & 126 & $21 \%$ \\
\hline Neutral & 58 & $9.7 \%$ \\
\hline Disagree & 294 & $49 \%$ \\
\hline Strongly disagree & 28 & $4.7 \%$ \\
\hline \multicolumn{3}{|c|}{ It is dangerous to take traditional eye medicines with modern eye medicines. } \\
\hline Strongly Agree & 38 & $6.3 \%$ \\
\hline
\end{tabular}




\begin{tabular}{|lll|}
\hline Questions & Frequency & Percent \\
\hline Agree & 220 & $36.7 \%$ \\
\hline Neutral & 39 & $6.5 \%$ \\
\hline Disagree & 275 & $45.8 \%$ \\
\hline Strongly Disagree & 28 & $4.7 \%$ \\
\hline Traditional eye medicines are more effective than modern eye medicines & \\
\hline Strongly agree & 19 & $3.2 \%$ \\
\hline Agree & 44 & $7.3 \%$ \\
\hline Neutral & 24 & $4 \%$ \\
\hline Disagree & 340 & $56.7 \%$ \\
\hline Strongly disagree & 173 & $28.8 \%$ \\
\hline Consulting eye care professional or pharmacist before applying traditional eye & medicine is important. \\
\hline Strongly agree & 21 & $3.5 \%$ \\
\hline Agree & 192 & $32 \%$ \\
\hline Neutral & 25 & $4.2 \%$ \\
\hline Disagree & 307 & $51.2 \%$ \\
\hline Strongly disagree & 55 & $9.1 \%$ \\
\hline
\end{tabular}

\section{Factors associated with the attitude towards traditional eye medicine use}

In this study, males were 2.00 times $(\mathrm{AOR}=2.00(95 \% \mathrm{Cl}: 1.23-2.68))$ more likely to have a good attitude towards TEM use compared to females. Study participants with a family history of TEM use were 3.31 times (AOR $=3.31(95 \% \mathrm{Cl}: 2.01-5.47)$ ) more likely to have a good attitude towards TEM use compared to those without a family history of TEM use.

Study participants, who live in traditional healer available area, were 1.82 times (AOR $=1.81(95 \% \mathrm{Cl}$ : 1.12-2.95)) more likely to have a good attitude towards TEM use compared to those who live in an area where traditional healer doesn't exist.

Study participants without health insurance were 1.63 times (AOR $=1.63(95 \% \mathrm{Cl}: 1.14-2.55)$ ) more likely to have a good attitude towards TEM use compared to those who had health insurance (Table 3 ).

Table 3: Factors associated with the attitude of study participants towards traditional eye medicine use among adults in Gondar city, North West Ethiopia, 
2017 ( $\mathrm{n}=292 \mathrm{n}=$ study participants with a good attitude) 


\begin{tabular}{l|l|l|l}
\hline Variable & Attitude & COR((95\%CI) & AOR(95\%CI) \\
\hline & Good & Poor & \\
\hline
\end{tabular}

Age (in year)

$\begin{array}{cccc}18-24 & 78 & 72 & 1.00 \\ 24-30 & 91 & 90 & 0.93(0.61-1.44) \\ 30-40 & 63 & 77 & 0.76(0.48-1.20) \\ 41-88 & 60 & 69 & 0.80(0.50-1.29)\end{array}$

Sex

\begin{tabular}{llllc} 
Male & 148 & 98 & $2.20(1.58-3.06)$ & $2.00(1.23-2.68)^{* *}$ \\
\hline Female & 144 & 210 & 1.00 & 1.00
\end{tabular}

Marital status

\begin{tabular}{llll} 
Married & 148 & 159 & 1.00 \\
\hline Unmarried & 144 & 149 & $1.04(0.75-1.43)$
\end{tabular}

\section{Educational status}

$\begin{array}{lrrl}\text { Illiterate } & 30 & 39 & 0.63(0.36-1.08) \\ \text { Read and write } & 38 & 61 & 0.51(0.31-0.82) \\ \text { Primary school } & 42 & 47 & 0.73(0.44-1.19) \\ \text { Secondary school } & 65 & 66 & 0.80(0.52-1.24) \\ \text { College and above } & 117 & 95 & 1.00\end{array}$

\section{Religion}

$\begin{array}{lccc}\text { Christian } & 260 & 279 & 1.00 \\ \text { Muslim } & 32 & 29 & 1.18(0.69-2.01)\end{array}$

\section{Occupation}

$\begin{array}{lccl}\text { Student } & 50 & 47 & 1.00 \\ \text { Housewife } & 39 & 70 & 0.52(0.30-0.92) \\ \text { Merchant } & 58 & 57 & 0.96(0.56-1.64) \\ \text { Employed } & 114 & 89 & 1.20(0.74-1.96 \\ \text { Others } & 31 & 45 & 0.65(0.35-1.19)\end{array}$

Income

$\begin{array}{llll}\text { High } & 217 & 209 & 1.00 \\ \text { low } & 75 & 99 & 0.73(0.51-1.04)\end{array}$

\section{Community leadership role}

$\begin{array}{llll}\text { Yes } & 54 & 61 & 0.92(0.61-1.40) \\ \text { No } & 238 & 247 & 1.00\end{array}$

\section{Awareness of TEM side effects}

\begin{tabular}{llll} 
Yes & 125 & 77 & 1.00 \\
\hline No & 167 & 231 & $0.45(0.32-0.63)$
\end{tabular}

\section{Availability of TH}


No

\section{Accessibility of modern eye care service}

Yes

No

Health insurance

Yes

No

188

269

188

104

44

248

Family history of TEM

\begin{tabular}{ccccc}
\hline Yes & 109 & 34 & $4.8(3.13-7.37)$ & $3.31(2.01-5.47)^{* *}$ \\
\hline No & 183 & 274 & 1.00 & 1.00 \\
\hline
\end{tabular}

$* *=$ p- value $<0.01$

\section{Discussion}

In this study, the Proportion of good attitude towards TEM use was 48.7\% (95\% Cl: 44.7-52.7\%). Almost half of the respondents had a good attitude towards TEM use. This result is higher than the study conducted in Jara town, Bale zone, South East Ethiopia (39.8 \%) (9). The possible explanation for this might be due to cultural and socioeconomic variation. Jara is a small town while Gondar is a zonal city, where study participants may have good information about traditional eye medicine. On the other hand, this result is lower than other studies done in Iran (75\%) (10), Singapore (92\%) (11), and China (63\%) (12). This difference could be because of variation in the study setting. These studies were done in hospital health care staffs, medical students, and pharmacists respectively. Besides this, traditional medicine practices are commonly available in Asians and used as alternative health care $(13,14)$.

Males were 2 times more likely to have a good attitude towards TEM use compared to females. Studies conducted in Israel (15), Serbia (16), and Tanzania (17) support this finding. This might be due to cultural tradition that parents usually transfer their skills and knowledge on traditional medicine to their male children. Moreover, males have higher community interaction than females. As a result, they could share information with their friends about traditional eye medicines.

Study participants with a family history of TEM use were 3.3 times more likely to have a good attitude towards TEM use compared to those without a family history of TEM use. This finding agrees with studies done in Malaysia (18) and Uganda (19). This might be a result of learning from family experience about health roles and the adverse effects of traditional eye medicine use.

Study participants who live in an area having traditional healer were 1.81 times more likely to have a good attitude towards TEM use compared to those who live in an area where traditional healer doesn't exist.

This is consistent with studies conducted in Nigeria $(20,21)$. It could be that persons nearby to traditional healers are more exposed to TEM practice and also appreciate the activity of traditional healers. 
Study participants without health insurance were 1.63 times more likely to have a good attitude towards TEM use compared to those who had health insurance.

This might be due to money constraints that participants couldn't visit the modern eye care center. For instance, $29 \%$ of the study participants in this study had less than 1, 328 Ethiopian total birrs monthly income.

As a result, they could stick to traditional eye medicines and their attitude towards TEM use might be better.

\section{Conclusion}

The result of this study shows that attitude towards traditional eye medicine use for the treatment of eye disease was fairly good. It indicates that almost half of the study participants had a good attitude towards traditional eye medicine use. Even though the attitude is fairly good, still it needs improvement. Male sex, family history of traditional eye medicine use, availability of traditional healers, and absence of health insurance had a statistically significant relationship with good attitude towards traditional eye medicine use. Community awareness creation through the joint up effort by the health ministry of Ethiopia and traditional healers about traditional eye medicine use can help to build the right perception and reduce the risk of complications.

\section{Limitation}

This study has had limitations to abolish social desirability and recall biases.

\section{Abbreviations}

$\mathrm{IQR}=$ Inter Quartile range

TEM = Traditional Eye Medicine

$\mathrm{TH}=$ Traditional Healer

\section{Declarations}

Ethical approval Ethical clearance was obtained from University of Gondar College of medicine and health sciences, School of Medicine Ethical Review Committee and support letter was obtained from local kebele administrates. The household head saw and read it during data collection. Since the data collection procedure was noninvasive, Verbal informed consent was obtained from all study participants to reduce participation withdrawal. This was approved by Gondar University School of Medicine Ethical Review committee. The confidentiality of the data was ensured and the consent declared that participants' participation is voluntary. They were also informed that there is no risk through participating in this survey. It was also clarified that they have full right to refuse from participating in the study and 
withdraw from the study at any time they wish. They would also have a full right to contact and ask the authors whatever they want.

Competing interest The authors report that there is no conflict of interest in this work

\section{Consent to publication}

This is not applicable because it doesn't consist of an individual's data

\section{Availability of data and materials}

Data set, on which the conclusion was made, is available on request from Mr. Minychil Bantihun (contact address: minychilmedban@gmail.com).

\section{Funding}

The University of Gondar has provided financial support for fieldwork (data collection only) of this research project. But the cost of data processing and analysis were covered by the principal investigator (Minychil Bantihun)

\section{Authors' contributions}

MB developed the proposal and analyzes and writes up the paper, DH and NL reviewed the proposal and final paper and prepares the manuscript. All the authors reviewed and approved the final manuscript.

\section{Acknowledgment}

The authors thank Gondar city administration office and all study participants for their cooperation and willingness.

\section{References}

1. Chan M. World health organization Congress on Traditional Medicine. World Health Organization. 2008; 8:66.

2. Ekeanyanwu Chuwuma Raphael. Traditional medicine in Nigeria: current status and the future. Research journal of pharmacology. 2011; 5(6):90-94.

3. Choudhary P, Chalisgaonkar C, Marathe P, Lakhtakia S. Use of traditional eye medicines by patients with a corneal ulcer in India. International Journal of Medical Science, Public Health. 2015; 4:100105 .

4. JA Ebeigbe. Traditional eye medicine practice in Benin-City, Nigeria. South African Optometry. 2013; 72(4):167-73.

5. Omolase C, Mahmoud A. Perceptions of Nigerian ophthalmologists about traditional eye care practice in Nigeria. African Journal of Medical Science. 2008; 37, 255-59. 
6. Venkatesh P, Pillai M, Manimegalai T, Srinivasan M. Use of traditional eye medicines by corneal ulcer patients presenting to a hospital in South India. Indian Journal of Ophthalmology. 1999;47:15-18

7. Samuel MW, Leul L, Belaynew WT, Laychiluh BM. Knowledge, Attitude, and Utilization of Traditional Medicine among the Communities of Merawi Town, Northwest Ethiopia, A Cross-Sectional Study. Evidence-Based Complementary and Alternative Medicine. 2015.

8. Kebede D, Binyam G, Yenus M "A historical overview of traditional medicine practices and policy in Ethiopia. The Ethiopian Journal of Health Development. 2006; 20(2):128-34.

9. Ahmed YM, Muhammed awel K, Ashebir D. Knowledge, Attitude and Practice of Community on Traditional Medicine in Jara Town, Bale Zone South East Ethiopia. Science Journal of Public Health. 2016; 4(3):241-46.

10. Mohsen A, Masoumeh $\mathrm{H}$. Knowledge, attitude and practice toward complementary and traditional medicine among Kashan health care staff, Iran. Complementary Therapies in Medicine. 2014; 22: $126-32$.

11. Mirzai V, Saiadi A, Heydarinasab M. Knowledge and attitude of Rafsanjan physicians about complementary and alternative medicine. Zahedan J Res Med sci. 2011; 13:20-24.

12. Yeo A, Yeo J, Yeo C, Lee C, Lim L, Lee T. Perceptions of complementary and alternative medicine amongst medical students in Singapore, a survey. Acupuncture in Medicine. 2005; 23:19-26.

13. Alkharfy.K.M. Community pharmacists' knowledge, attitudes, and practices towards herbal remedies in Riyadh, Saudi Arabia. Eastern Mediterranean Health Journal. 2010; 16, 9.

14. Al-Saeedi $\mathrm{M}$ et al. Patterns of belief and use of traditional remedies by diabetic patients in Mecca, Saudi Arabia. Eastern Mediterranean Health Journal. 2003, 9(1-2):99-07.

15. Freda G. Knowledge levels and attitudes of staff nurses in Israel towards complementary and alternative medicine. Journal of Advanced Nursing (J Adv Nurs). 2001, 36(1):41-48.

16. Isidora Sea. Consumers' attitude towards the use and safety of herbal medicines and herbal dietary supplements in Serbia. International Journal of Clinical Pharmacology. 2013; 35:835-40.

17. Ndrea SW, Michael M, Michael O, Bartholomayo M, Erich S, Louise J-A. Attitudes Towards African Traditional Medicine and Christian Spiritual Healing Regarding Treatment of Epilepsy in a Rural Community of Northern Tanzania. African journal of traditional and Complement Alternative Medicine.2010; 7(2):162-70.

18. Azrian. Women's attitude and sociodemographic characteristics influencing usage of herbal medicines during pregnancy in tumpat district, Kelantan, Malaysia. BMC Complement Alternative Medicine. March 2009, 40, 2.

19. Fortunate a. Health-care seeking behavior and the use of traditional medicine among persons with type 2 diabetes in south-western Uganda. Pan African Medical Journal. 2015; 20:76.

20. Adepoju GK. The Attitudes and Perceptions of Urban and Rural Dwellers To Traditional Medical Practice in Nigeria: A Comparative Analysis. International Journal of Gender and Health Studies. 2005; Vol. 3 (No. 1 and 2):190-01. 
21. Aluko T. Trading in Traditional Medicine: The Challenges for Womanhood and the Health Care System in Nigeria. International Journal of Gender and Health Studies. 2005; Vol. 2(No 1 and 2): 4754.

\section{Figures}

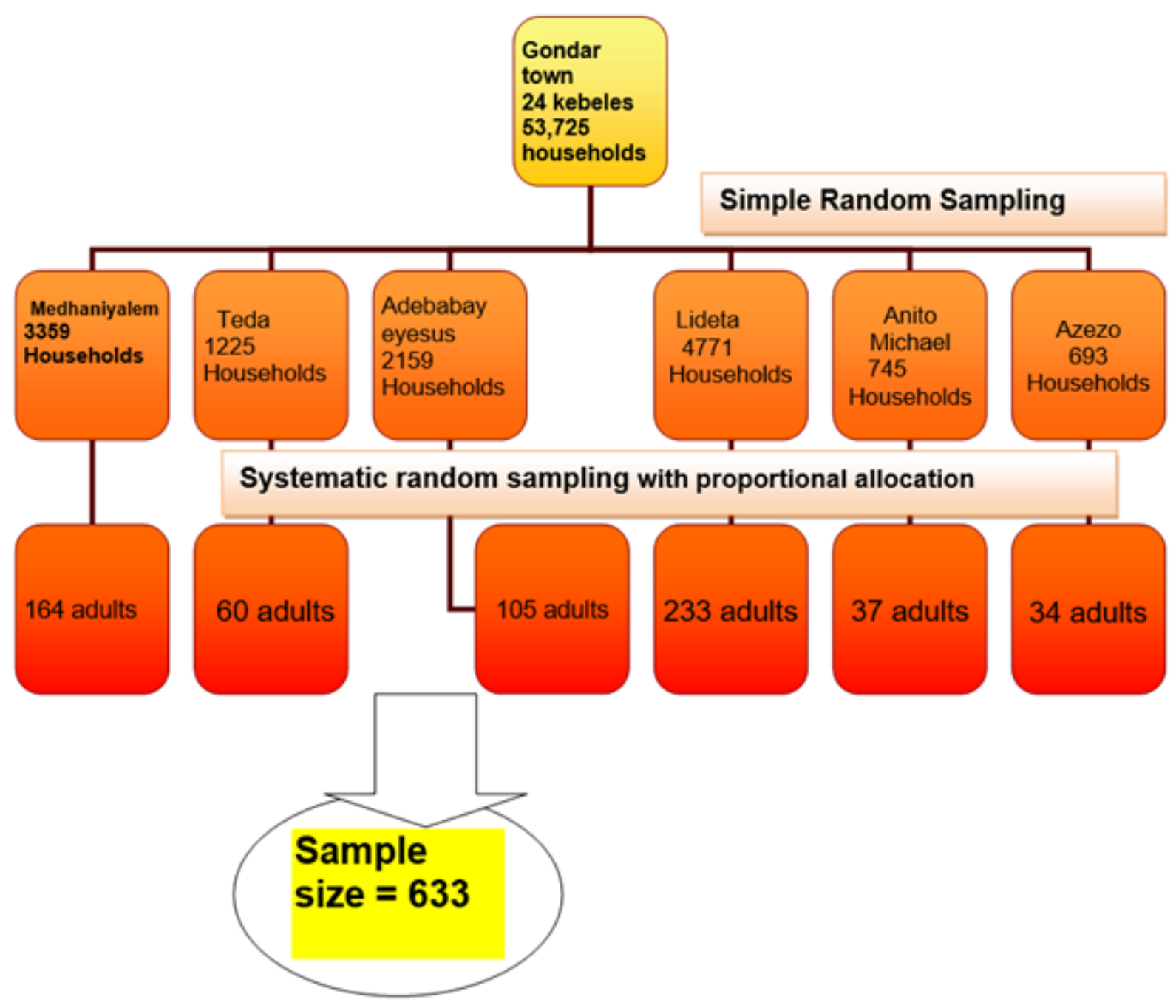

Figure 1

Diagrammatic representation of sampling procedure among adults in Gondar city, North West Ethiopia 